\title{
Effects of a probiotic preparation on the human faecal microflora and biochemical and haematological parameters
}

\author{
Alice Lan ${ }^{\mathrm{a}, *}$, Rong-Hong Hsieh ${ }^{\mathrm{b}}$, Cheng-Chih Tsai ${ }^{\mathrm{c}}$, Chun-Chih Huang ${ }^{\mathrm{a}}$ \\ ${ }^{a}$ New Bellus Enterprises Co., Ltd., 48 Industrial Road, Tainan City 72042, Taiwan \\ b School of Nutrition and Health Sciences, 250 Wuxing Street, Taipei City110, Taiwan \\ c Department of Food Science and Applied Biotechnology, Hung Kuang University, No. 1018, Sec. 6, \\ Taiwan Boulevard, Shalu District, Taichung City 43302, Taiwan
}

*Corresponding author, e-mail: alicelan.nb@gmail.com

Received 19 Mar 2015

Accepted 16 Jun 2015

\begin{abstract}
The aim of this study was to investigate the effects of supplementation of a probiotic preparation PROBIO-C containing Lactobacillus acidophilus, Bifidobacterium longum, L. rhamnosus, and Streptococcus thermophilus on the intestinal microflora of healthy volunteers and the effects on biochemical and haematological measurements. In vitro analyses, which included acid and bile salts tolerance and adhesion tests, were performed first. Probiotic bacteria in PROBIO-C demonstrated adhesion to human intestinal Caco-2 cells. An intervention study was conducted in a single-blind, random, and placebo-controlled trial. Twenty-four healthy volunteers were randomly assigned to one of three treatment groups, one provided with the placebo powder excluding the probiotic, one with $3 \mathrm{~g}$ of PROBIO-C with a targeted dose of $1.5 \times 10^{11} \mathrm{CFU}$ of probiotic bacteria, and one with $6 \mathrm{~g}$ of PROBIO-C with a targeted dose of $3 \times 10^{11} \mathrm{CFU}$ of probiotic bacteria. The experiment comprised three phases: the control period (week 1) during which no supplementation was given; the test period (weeks 2-4) during which volunteers were given either the placebo sample or PROBIO-C each day; the post-test period (week 5) during which no supplementation was given. The faecal samples were collected once every week throughout the study. The abundances of Bifidobacterium and Lactobacillus species increased significantly during the test period in both PROBIO-C supplemented groups. In addition, the probiotic supplementation did not result in any significant change in clinical chemistry and haematological parameters. The results from this pilot study indicated that PROBIO-C is well-tolerated and safe.
\end{abstract}

KEYWORDS: intestinal microflora, intervention study, probiotics

\section{INTRODUCTION}

Probiotic, a Greek term meaning 'for life', was initially defined by Lilly and Stillwell in 1954 to refer to any substance secreted by a microorganism that inhibits the growth of another microorganism ${ }^{1}$. Many other definitions were then proposed; and it was not until 1992 that Havennar and Huis In't Veld re-defined the term 'probiotic' as referring microorganisms that can survive in the intestinal tract, modulate the intestinal microflora population, and confer a health benefit to the host ${ }^{2}$. For example, bifidobacteria and lactobacilli are capable of enhancing intestinal resistance to pathogenic infections, reducing cholesterol levels, modulating the immune response, and producing vitamins $\mathrm{s}^{3,4}$.

Changes in the diet, psychological stress, environmental factors or raging can cause an increase in the number of pathogens. This may further result in dysbiosis of intestinal microflora, which increases susceptibility to infection. Probiotics provide resistance to invasion of pathogenic and opportunistic microorganisms by competitive exclusion and enhancement of host barrier defences ${ }^{5-7}$. Dietary prebiotics are natural or fortified foods and fermented ingredients, which modulate the composition and function of the intestinal microflora, hence conferring a health benefit.

Lactobacilli are facultative anaerobic and catalase-negative organisms ${ }^{8}$. Lactobacillus species are capable of colonizing the intestinal flora and provide a niche for vitamin $\mathrm{B}$ and vitamin $\mathrm{K}$ biosynthesis. Lactobacillus species exert anti-tumour activity with regard to colon cancers ${ }^{9-11}$, improve clinical symptoms in patients with ulcerative colitis ${ }^{12}$, relieve constipation in individuals on low-calorie diets ${ }^{13}$, reduce allergy symptoms ${ }^{14}$, and lower total cholesterol levels in animal studies ${ }^{15}$. Combined supplementation of Lactobacillus and Bifidobacterium species may ameliorate symptoms of collagenous 
colitis $^{16}$. Heat-killed Lactobacillus acidophilus also shortens the recovery time for non-rotavirus diarrhoea in children ${ }^{17}$, and prevents antibiotic-associated diarrhoea in hospitalized patients ${ }^{18}$. Allergies may also be prevented by oral supplementation of Lactobacillus and Bifidobacterium species ${ }^{19}$. L. rhamnosus has been shown to have antimicrobial effects against enteric pathogens, such as rotavirus $^{20-22}$. Streptococcus thermophilus is commonly found in high- and low-temperature pasteurized milk products, e.g., cheese, and yoghurt. $S$. thermophilus and their secretory products can strengthen the barrier function of the small intestine and stimulate T helper 1 immune responses ${ }^{23}$. S. thermophilus ameliorates the clinical symptoms of mucositis in patients receiving chemotherapy ${ }^{24}$, and may also decrease the degree of inflammation and increase the thickness of the gastric lining ${ }^{25}$.

If microorganisms are to be used as a probiotic, they must be safe, remain viable during both the industrial production processes and intestinal transit, adhere to the intestinal mucosa, and persist in the gastrointestinal tract to exert an effect. Probiotic species must be able to withstand the host's natural defences against ingested microorganisms, and harsh conditions, such as gastric acid and bile salts, which are two major impediments for their survival in the gastrointestinal tract. Bacteria in the two genera of Lactobacillus and Bifidobacterium species are important residents of intestinal microflora and are known to resist these conditions. It is difficult to predict the survivability of probiotic strains in vivo, and thus the adhesion and resistance to acid and bile salts should be tested in vitro to evaluate their suitability in a multispecies probiotic preparation. Probiotics must have the ability to modulate the composition of microflora. To test the properties needed for useful probiotics, this study first investigated in vitro adhesion and tolerance to acid and bile salts; second, it enumerates important groups by selective agar culturing; and third, it evaluates the effects of the probiotic preparation on routine biochemical and haematological parameters in healthy volunteers in an intervention study.

\section{MATERIALS AND METHODS}

\section{Test materials}

The PROBIO-C probiotic preparation contains L. acidophilus LA107, Bifidobacterium longum BL268, L. rhamnosus LCR177, and S. thermophilus ST136. Other ingredients include xylooligosaccharides, isomalto-oligonucleotides, xylitol, water-soluble diet- ary fibre, sucralose, and yoghurt flavour powder. The placebo powder had the same recipe as the probiotic preparation, except for the probiotic bacteria, and was identical in appearance and taste.

\section{Acid and bile salts tolerance}

One $\mathrm{ml}$ of probiotic culture $\left(10^{9} \mathrm{CFU}\right)$ was added to $9 \mathrm{ml}$ of phosphate buffered saline (PBS), which was previously adjusted to $\mathrm{pH} 2.0,2.5$, or 3.2 . PBS with $\mathrm{pH} 7.2$ served as a control. After $3 \mathrm{~h}$ incubation at $37^{\circ} \mathrm{C}$, the culture was serially ten-fold diluted and poured onto MRS agar plates. The plates were incubated at $37^{\circ} \mathrm{C}$ for $48 \mathrm{~h}$. The colonies were counted and subcultured at $\mathrm{pH} 2.0$ and $37^{\circ} \mathrm{C}$ for $3 \mathrm{~h}^{26}$. After centrifugation at $4200 \mathrm{~g}$, the pellet was washed once with PBS and resuspended. The bacterial culture was added to $9 \mathrm{ml}$ MRS medium with or without $0.3 \%$ ox gall bile salts and incubated for 3,12 , and $24 \mathrm{~h}$. The incubated culture was then ten-fold serially diluted and plated onto MRS agar ${ }^{27,28}$.

\section{Adhesion to human intestinal cells}

Seventy to eighty percent confluent Caco-2 cells were initially cultured in a T75 flask. The media was removed and the cells were washed twice with PBS. Then, $1 \mathrm{ml}$ of trypsin/EDTA was added for cell dissociation, and $40 \mathrm{ml}$ DMEM containing FBS and penicillin-streptomycin was used to inactivate the trypsin enzyme. Then $0.5 \mathrm{ml}\left(10^{4} \mathrm{cell} / \mathrm{ml}\right)$ of Caco2 cell suspension was added to each well (24-well plate with coverslips). The plate was incubated with $10 \% \mathrm{CO}_{2}$ and at $37^{\circ} \mathrm{C}$ overnight for proper adhesion and growth. On the next day, the cells were washed twice with PBS and refreshed with $0.5 \mathrm{ml}$ DMEM medium without penicillin-streptomycin. Then, $100 \mu \mathrm{l}$ of bacterial culture $\left(10^{7} \mathrm{CFU} / \mathrm{ml}\right)$ was added to each well, and the plate was incubated with $10 \% \mathrm{CO}_{2}$ and at $37^{\circ} \mathrm{C}$ for $2 \mathrm{~h}$. At the end of the incubation, each well was washed with PBS three times and then fixed with $200 \mu 110 \%$ formalin for $30 \mathrm{~min}$. The cells were stained with filtered crystal violet solution in a dark box for 5 min. Excess staining was removed by washing with $0.5 \mathrm{ml}$ of PBS. The coverslip was removed and a drop of PBS was added to prevent drying. The cell count was performed using a Nikon microscope.

\section{Intervention study}

The study was approved by the Institutional Review Board of Taipei Medical University (approval number CRC-05-10-05). In total, 24 healthy participants completed the study ( 8 males and 16 females; average age $24.1 \pm 3.5$; average weight $55 \pm 10 \mathrm{~kg}$ ), 
and these were randomly divided into 3 groups (eight per group): one group received a single-dose of PROBIO-C, the second group received a doubledose of PROBIO-C, and the third group received the placebo. A single dose was $3 \mathrm{~g}$ of PROBIO-C powder dissolved in 150-200 $\mathrm{ml}$ of water, and doubled amounts of the PROBIO-C powder and water were consumed by the double-dose group.

This study comprised three phases: the control (week 1), test (weeks 2-4), and post-test periods (week 5). During the control period, no PROBIO-C was given. This was followed by a three-week supplementation of PROBIO-C (test period). During the post-test period, the participants stopped taking PROBIO-C. The participants were asked to take the designated dose of PROBIO-C or placebo during weeks 2-4. Faecal samples were collected once every week throughout the study (5 weeks in total) and subjected to enumeration analysis. Blood samples were collected at the baseline and at the end of supplementation period for biochemical and haematological measurements.

\section{Analysis of faecal microflora}

Stools were collected in closed containers to maintain anaerobic conditions. The samples were then transferred to an anaerobic glove box. A weighed sample $(\sim 0.5 \mathrm{~g})$ was added to $4.5 \mathrm{ml}$ of anaerobic dilution media (containing five glass beads) and vortexed.

Under anaerobic conditions, the homogenate was ten-fold serially diluted and plated onto MRS agar either by the spread plate or pour plate methods. The plates were cultured at $35-37^{\circ} \mathrm{C}$ in an anaerobic glove box or anaerobic chamber, which contained anaerobic packs or with oxygen removal by suction. The resulting colonies were then counted.

Total anaerobic bacterial counts were enumerated by CDC anaerobe blood agar plate. Lactobacillus species counts were determined by using MRS Broth (Difco) as the base media with additives of 2-phenylethyl alcohol and bromocresol green. To analyse the total bifidobacteria population, bifidobacteria iodoacetate medium-25 (BIM25) plates were used. Clostridium perfringens population was enumerated using tryptose-sulphite-Dcycloserine (TSC) agar, whereas Endo agar was used for coliform organisms.

\section{Statistical analysis}

ANOVA was first used to determine any differences among the experimental phases (control, test, and
Table 1 Survival of PROBIO-C probiotics at different $\mathrm{pH}$.

\begin{tabular}{lcc}
\hline $\mathrm{pH}$ & \multicolumn{2}{c}{ Bacterial counts $^{\dagger}$} \\
\cline { 2 - 3 } & $0 \mathrm{~h}$ & 3 h later \\
\hline 2.0 & $10.54 \pm 0.15$ & $10.66 \pm 0.39$ \\
2.5 & $10.32 \pm 0.23$ & $10.51 \pm 0.33$ \\
3.2 & $10.63 \pm 0.41$ & $10.71 \pm 0.21$ \\
7.2 & $10.59 \pm 0.54$ & $10.62 \pm 0.34$ \\
\hline${ }^{\dagger}$ Bacterial counts are converted to $\log _{10} \mathrm{CFU} / \mathrm{ml}$.
\end{tabular}

Table 2 Time course effects of bile salts on the growth of acid-treated ( $\mathrm{pH}$ 2.0) probiotics.

\begin{tabular}{|c|c|c|}
\hline \multirow[t]{2}{*}{ Time } & \multicolumn{2}{|c|}{ Bacterial counts ${ }^{\dagger}$} \\
\hline & MRS & MRS-bile \\
\hline $0 \mathrm{~h}$ & $10.32 \pm 0.28$ & $10.32 \pm 0.28$ \\
\hline $3 \mathrm{~h}$ later & $10.35 \pm 0.23$ & $10.41 \pm 0.62$ \\
\hline $12 \mathrm{~h}$ later & $10.69 \pm 0.36$ & $10.45 \pm 0.32$ \\
\hline $24 \mathrm{~h}$ later & $10.73 \pm 0.85$ & $10.53 \pm 0.12$ \\
\hline
\end{tabular}

post-test periods). Tukey's HSD test was then applied to determine any significant differences among groups at the $95 \%$ confidence interval.

\section{RESULTS}

This study used an artificial phosphate buffered system to expose lactic acid bacteria to $\mathrm{pH} 2.0$, $\mathrm{pH} 2.5, \mathrm{pH} 3.2$, and $\mathrm{pH} 7.2$ for $3 \mathrm{~h}$. The original CFU of PROBIO-C at $10^{10} \mathrm{CFUs} / \mathrm{ml}$ could still be maintained after $3 \mathrm{~h}$ incubation at $\mathrm{pH} 2.0$ (Table 1). MRS medium with or without $0.3 \%$ bile salts was added to the culture which had previously been incubated for $3 \mathrm{~h}$ at $\mathrm{pH} 2.0$. After $24 \mathrm{~h}$ incubation, the CFU of PROBIO-C cultured in MRS with $0.3 \%$ bile salts was not statistically different from that in MRS alone (Table 2). As shown in Table 3, the adhesion of each individual bacterial strain was similar, although the PROBIO-C including four strains demonstrated a higher adhesion $(35.7 \pm 5.4 \mathrm{CFU} /$ cell $)$ than any of the single strains alone.

Participants received a total of $6 \times 10^{10} \mathrm{CFU}$ bacteria (single-dose group) or $12 \times 10^{10} \mathrm{CFU}$ bacteria (double-dose group). As shown in Table 4, after three-week supplementation the total anaerobic bacterial counts increased from $11.05 \pm 0.74$ (mean $\log _{10} \mathrm{CFU} / \mathrm{g}$ wet weight of faeces $\pm \mathrm{SD}$ ) to $12.1 \pm 1.1 \log _{10} \mathrm{CFU} / \mathrm{g}$ in participants receiving a single-dose (3 $\mathrm{g}$ of PROBIO-C), but returned to the baseline numbers during the post-test period. Similarly, Lactobacillus counts increased after 3 weeks 
Table 3 Adhesion of PROBIO-C bacteria to the human Caco-2 cells.

\begin{tabular}{lc}
\hline Bacteria & $\begin{array}{c}\text { Number of adhered bacteria } \\
\text { (CFU/cell) }\end{array}$ \\
\hline S. thermophilus & $25.3 \pm 2.6$ \\
L. rhamnosus & $28.4 \pm 5.6$ \\
L. acidophilus & $23.4 \pm 3.9$ \\
B. longum & $21.9 \pm 4.9$ \\
PROBIO-C & $35.7 \pm 5.4$ \\
\hline
\end{tabular}

(9.25 $\left.\pm 0.90-10.78 \pm 0.72 \log _{10} \mathrm{CFU} / \mathrm{g}\right)$. There was already a significant increase in the bifidobacteria counts after 2 weeks $(10.86 \pm 0.65)$, and the trend continued to the third week $(11.10 \pm 0.78)$. However, during the post-test period the bifidobacteria counts returned to the same level as during the pretest period. The TSC and Endo counts for $C$. perfringens and coliform organisms, respectively, did not change significantly during the test or post-test periods. An increase in total anaerobic bacterial count was observed in the group receiving $6 \mathrm{~g}$ of PROBIO-C after 2 weeks of PROBIO-C supplementation $(10.64 \pm 0.91-12.03 \pm 0.96)$, and maintained at $12.0 \pm 1.1$ at the end of the test period. However, the number returned to the baseline $(11.7 \pm 1.1)$ during the post-test period (Table 4). Lactobacilli counts were higher than the baseline counts after three-week supplementation $(8.46 \pm 0.91-9.7 \pm 1.4)$, but returned to the baseline during the post-test period. The abundance of bifidobacteria at week 3 of the test period was higher $(10.99 \pm 0.62)$ compared to the baseline (9.75 \pm 0.56$)$. Abundances of $C$. perfringens and coliforms organisms did not change significantly during the test and post-test periods. For the placebo group, no significant changes were observed in total numbers of anaerobic bacteria, lactobacilli, and bifidobacteria during the test and post-test periods (Table 4). No significant changes were observed in the counts of $C$. perfringens and coliform organisms.

Biochemical and haematological measurements before and after PROBIO-C supplementation are shown in Table 5 and Table 6. No significant difference was observed for clinicobiochemical and haematological parameters. All values were within the normal range of reference values.

\section{DISCUSSION}

The ability to adhere to the intestinal epithelium is important for the survival and colonization of probiotics species. Gilliland et al suggested that

Table 4 Average bacterial counts in faecal samples as determined by selective enumeration.

\begin{tabular}{|c|c|c|c|c|c|}
\hline \multirow[t]{2}{*}{ Group $^{\dagger}$} & \multicolumn{5}{|c|}{ Bacterial counts, mean \pm SD ( $\log _{10} \mathrm{CFU} / \mathrm{g}$ wet weight of faeces) } \\
\hline & week $1^{*}$ & week 2 & week 3 & week 4 & week 5 \\
\hline \multicolumn{6}{|c|}{ Single-dose group (3 g of PROBIO-C) } \\
\hline CDC & $11.05 \pm 0.74^{\mathrm{a}}$ & $10.92 \pm 0.72^{\mathrm{a}}$ & $11.35 \pm 0.66^{\mathrm{ab}}$ & $12.1 \pm 1.1^{\mathrm{b}}$ & $10.98 \pm 0.76^{\mathrm{a}}$ \\
\hline MRS & $9.25 \pm 0.90^{\mathrm{ac}}$ & $9.6 \pm 1.0^{\mathrm{a}}$ & $10.0 \pm 1.0^{\mathrm{ab}}$ & $10.78 \pm 0.72^{\mathrm{b}}$ & $8.4 \pm 1.2^{\mathrm{c}}$ \\
\hline BIM & $9.17 \pm 0.95^{\mathrm{a}}$ & $9.83 \pm 0.68^{\mathrm{a}}$ & $10.86 \pm 0.65^{\mathrm{b}}$ & $11.10 \pm 0.78^{\mathrm{b}}$ & $9.24 \pm 0.86^{\mathrm{a}}$ \\
\hline TSC & $4.4 \pm 1.0$ & $4.06 \pm 0.64$ & $3.9 \pm 1.6$ & $3.6 \pm 1.9$ & $3.69 \pm 0.88$ \\
\hline Endo & $5.98 \pm 0.50$ & $6.05 \pm 0.81$ & $6.31 \pm 0.56$ & $6.7 \pm 1.4$ & $6.9 \pm 1.1$ \\
\hline \multicolumn{6}{|c|}{ Double-dose group (6 g of PROBIO-C) } \\
\hline $\mathrm{CDC}$ & $10.64 \pm 0.91^{\mathrm{b}}$ & $11.48 \pm 0.85^{\mathrm{ab}}$ & $12.03 \pm 0.96^{\mathrm{a}}$ & $12.0 \pm 1.1^{\mathrm{a}}$ & $11.7 \pm 1.1^{\mathrm{ab}}$ \\
\hline MRS & $8.46 \pm 0.91^{\mathrm{a}}$ & $9.52 \pm 0.34^{\mathrm{ab}}$ & $9.56 \pm 0.64^{\mathrm{ab}}$ & $9.7 \pm 1.4^{\mathrm{b}}$ & $9.38 \pm 0.32^{\mathrm{ab}}$ \\
\hline BIM & $9.75 \pm 0.56^{\mathrm{a}}$ & $10.50 \pm 0.49^{\mathrm{ab}}$ & $10.7 \pm 1.2^{\mathrm{ab}}$ & $10.99 \pm 0.62^{b}$ & $10.04 \pm 0.61^{\mathrm{ab}}$ \\
\hline TSC & $5.4 \pm 1.4$ & $4.7 \pm 1.5$ & $4.0 \pm 1.0$ & $4.2 \pm 1.5$ & $3.9 \pm 1.6$ \\
\hline Endo & $6.1 \pm 1.2$ & $5.6 \pm 1.5$ & $6.66 \pm 0.86$ & $6.54 \pm 0.88$ & $6.57 \pm 0.59$ \\
\hline \multicolumn{6}{|c|}{ Placebo group } \\
\hline $\mathrm{CDC}$ & $11.09 \pm 0.68$ & $11.02 \pm 0.45$ & $11.33 \pm 0.76$ & $12.3 \pm 1.1$ & $11.48 \pm 0.81$ \\
\hline MRS & $9.12 \pm 0.96$ & $9.08 \pm 0.47$ & $8.9 \pm 1.2$ & $9.4 \pm 1.0$ & $9.00 \pm 0.97$ \\
\hline BIM & $9.43 \pm 0.97$ & $9.36 \pm 0.54$ & $9.2 \pm 1.2$ & $9.5 \pm 1.4$ & $9.5 \pm 1.0$ \\
\hline TSC & $4.9 \pm 1.2$ & $4.7 \pm 1.1$ & $4.6 \pm 1.3$ & $4.23 \pm 0.67$ & $4.0 \pm 1.6$ \\
\hline Endo & $6.42 \pm 0.93$ & $6.2 \pm 1.0$ & $6.88 \pm 0.61$ & $7.08 \pm 0.54$ & $7.14 \pm 0.86$ \\
\hline
\end{tabular}

$\dagger$ CDC: total anaerobic bacterial counts; MRS: Lactobacillus species; BIM: Bifidobacterium species; TSC: C. perfringens; Endo: coliform group.

*Week 1: before the test period; weeks 2-4: during the test period; week 5: during the post-test period. Values with different superscript letters were significantly different $(p<0.05)$. 
Table 5 Effects of PROBIO-C on clinicobiochemical parameters.

\begin{tabular}{lcc}
\hline Parameter $^{\dagger}$ & Baseline & Week 5 \\
\hline TG (mg/dl) & $57 \pm 19$ & $62 \pm 28$ \\
Cholesterol (mg/dl) & $160 \pm 43$ & $166 \pm 36$ \\
HDL-C (mg/dl) & $61 \pm 16$ & $62 \pm 14$ \\
LDL-C (mg/dl) & $98 \pm 24$ & $101 \pm 19$ \\
T-CHO/HDL & $2.77 \pm 0.66$ & $2.88 \pm 0.57$ \\
AST/SGOT (U/l) & $24.7 \pm 7.1$ & $25.7 \pm 6.8$ \\
ALT/SGPT (U/i) & $22 \pm 10$ & $24 \pm 12$ \\
\hline
\end{tabular}

$\dagger$ TG: triglyceride; HDL-C: high-density lipoprotein cholesterol; LDL-C: low-density lipoprotein cholesterol; T-CHO/HDL: total cholesterol/high-density lipoprotein cholesterol; AST/SGOT: aspartate aminotransferase/serum glutamic-oxaloacetic transaminase; ALT/SGPT: alanine aminotransferase/serum glutamic pyruvic transaminase. Changes between the baseline and at the end of intervention (week 5) are shown. Values are presented as the mean \pm SD.

Table 6 Effects of PROBIO-C on haematological parameters.

\begin{tabular}{lcc}
\hline Parameter $^{\dagger}$ & Baseline & Week 5 \\
\hline WBC $\left(10^{3} / \mu \mathrm{l}\right)$ & $5.8 \pm 1.6$ & $6.0 \pm 1.4$ \\
RBC $\left(10^{6} / \mu \mathrm{l}\right)$ & $4.70 \pm 0.90$ & $4.9 \pm 1.5$ \\
Haemoglobin $(\mathrm{g} / \mathrm{dl})$ & $13.5 \pm 2.6$ & $14.1 \pm 1.5$ \\
Haematocrit $(\%)$ & $40.6 \pm 7.7$ & $42.2 \pm 3.9$ \\
MCV $(\mathrm{fl})$ & $84 \pm 16$ & $86.9 \pm 6.0$ \\
MCH $(\mathrm{pg})$ & $28.0 \pm 5.3$ & $28.9 \pm 2.4$ \\
MCHC $(\mathrm{g} / \mathrm{dl})$ & $32.2 \pm 5.9$ & $33.28 \pm 0.98$ \\
Plate $\left(10^{3} / \mu \mathrm{l}\right)$ & $262 \pm 61$ & $266 \pm 48$ \\
\hline
\end{tabular}

$\dagger \mathrm{MCV}$ : mean corpuscular volume; MCH: mean corpuscular haemoglobin; MCHC: mean corpuscular haemoglobin concentration. Values are presented as the mean \pm SD.

bile salts tolerance is critical for lactic acid bacteria survival in the intestine ${ }^{28}$. Interestingly, most probiotics are more tolerant to bile salts than to acids ${ }^{29}$. The results from this study indicated that the 4 strains of bacteria in the probiotic preparation could survive reasonably well at low $\mathrm{pH}$ and in the presence of bile salts. For probiotic bacteria to exert their beneficial effects, they must adhere and at least transiently colonize the intestinal flora. In vitro testing of the adhesion ability of probiotic bacteria to human intestinal cells thus provides the first method of screening for suitable species. In this study, the probiotic preparation (4 strains) had better adhesion to human Caco-2 cells than any of the single strains alone. It is possible that other components in the probiotic preparation may enhance bacterial adhesion to the cells.

Mucosal microflora provides a more realistic microbial landscape of an individual. However, invasive procedures, such as biopsies are required to assess this, and certain anatomical regions, including the small intestine, are particularly difficult to sample. Hence faecal microflora have been widely used as a surrogate for the gut microflora. In this study, the consumption of $L$. acidophilus and B. longum in the probiotic preparation possibly accounted for increases in total bacterial counts and abundances of Lactobacillus and Bifidobacterium species. However, such increases were not observed in the post-test period. This phenomenon was also reported in other studies where increased abundances of probiotic species were only observed during the period of consumption. Interestingly, the uptake of the lactic acid bacteria does not necessarily result in their detection in the faecal samples. In one study, Lactobacillus counts did not increase after 3 weeks of daily supplementation of $10^{9} \mathrm{CFUs}$ of $L$. johnsonii $\mathrm{La} 1^{30}$.

The faecal counts for the probiotic species, such as lactobacilli and bifidobacteria, were elevated during the supplementation period, but once the supplementation ceased the numbers returned to the pretest levels ${ }^{31,32}$. In this study, the consumption of PROBIO-C including 4 probiotic strains, L. acidophilus, B. longum, L. rhamnosus, and S. thermophilus, likely contributed to the increases in the total count of anaerobic bacteria, lactobacilli, and bifidobacteria during the consumption period. Although their numbers then fell to the pretest level, this 'transient colonization' also means that they are safe to consume ${ }^{32}$. A recent study by Kim et al used pyrosequencing to examine the composition of the intestinal microflora in individuals receiving probiotics $^{33}$, and the results did not reveal any significant changes. As healthy microflora are fairly robust and not easily altered, short-term supplementation of probiotics may have limited capability to modify the intestinal microflora. On the other hand, individuals with intestinal diseases may benefit from consumption of probiotics, and the effects may be more pronounced than in other individuals. A study on patients with irritable bowel syndrome (IBS) showed similar results, as probiotic supplementation increased the faecal counts of lactobacilli and bifidobacteria, but counts for Clostridium species and Escherichia coli subgroup remained the same ${ }^{34}$. Despite no change in the abundances of pathogenic groups, patients still experienced significant relief from the IBS symptoms. Various pathogens also 
cause intestinal infections, which are characterized by having symptoms of vomiting and diarrhoea. Lactobacillus spp. have been shown to display antipathogenic properties against Vibrio cholerae and Klebsiella spp. ${ }^{35}$. Moreover, probiotics, including lactic acid bacteria, have been proposed to alleviate symptoms of coeliac disease ${ }^{36}$. The effects of the probiotic preparation could be further evaluated in individuals with IBS, or inflammatory bowel disease.

Probiotics have a long history of consumption and seem well-tolerated. In fact, some probiotics are often isolated from food ${ }^{37}$. Many probiotic supplements on the market belong to the category of 'functional foods', which means that they are usually not subjected to rigorous safety assessments. Few studies have reported the tolerability and safety of probiotic consumption of one strain and multiple strains. Cox et al demonstrated that probiotic supplementation of a single strain $B$. animalis lactis isolate BI-04 or a combination of $L$. acidophilus NCFM and $B$. animalis lactis BI-07 is generally safe ${ }^{38}$. Except for some minor changes in biochemical and haematological measurements, no significant safety concerns were reported $^{38}$. The authors also stressed the importance of safety assessments on different formulations and doses. The current study found no significant changes in either clinicobiochemical or haematological measurements at the end of consumption compared to the baseline. This study is one of the very few works that concurrently investigated the effects of probiotics on the faecal microflora while also carrying out routine laboratory measurements for safety monitoring.

This study showed that three-week supplementation at either targeted dose $6 \times 10^{10}$ or $12 \times 10^{10}$ $\mathrm{CFU}$ resulted in detection of Bifidobacterium and Lactobacillus species in faecal microflora. Routine laboratory measurements also indicated that the probiotic preparation is safe and well tolerated by healthy individuals. The results from this study also warrant further research with a longer supplementation period to examine the long-term effects, and it is anticipated that a reduced abundance of pathogens such as Clostridium and coliform groups may also be observed in such works.

Acknowledgements: The authors want to thank Ms Fang Yu Lin for helpful discussion on this manuscript.

\section{REFERENCES}

1. Lilly DM, Stillwell RH (1965) Probiotics: growth-promoting factors produced by microorganisms. Science
147, 747-8.

2. Havenaar R, Huis In't Veld JHJ (1992) Probiotics: a general view. In: Wood BJB (ed) Lactic Acid Bacteria in Health and Disease, Elsevier Applied Science Publishers, Amsterdam, pp 151-70.

3. Steer T, Carpenter H, Tuohy K, Gibson GR (2000) Perspectives on the role of the human gut microbiota and its modulation by pro- and prebiotics. Nutr Res Rev 13, 229-54.

4. Rashmi BS, Gayathri D (2014) Partial purification, characterization of Lactobacillus sp. G5 lipase and their probiotic potential. Int Food Res $J$ 21, 1737-43.

5. Fuller R, Gibson GR (1997) Modification of the intestinal microflora using probiotics and prebiotics. Scand J Gastroenterol 32, Suppl. 222, 28-31.

6. Servin AL (2004) Antagonistic activities of lactobacilli and bifidobacteria against microbial pathogens. FEMS Microbiol Rev 28, 405-40.

7. Penner R, Fedorak RN, Madsen KL (2005) Probiotics and nutraceuticals: non-medicinal treatments of gastrointestinal diseases. Curr Opin Pharmacol 5, 596-603.

8. Gibson GR, Roberfroid MB (1995) Dietary modulation of the human colonic microbiota: introducing the concept of prebiotics. $J$ Nutr 125, 1401-12.

9. Singh J, Rivenson A, Tomita M, Shimamura S, Ishibashi N, Reddy BS (1997) Bifidobacterium longum, a lactic acid-producing intestinal bacterium inhibits colon cancer and modulates the intermediate biomarkers of colon carcinogenesis. Carcinogenesis 18, 833-41.

10. Asha, Gayathri D (2012) Synergistic impact of Lactobacillus fermentum, L. plantarum and vincristine on 1,2-dimethylhydrazine-induced colorectal cancer in mice. Exp Ther Med 3, 1049-54.

11. Gayathri D, Asha, Devaraja TN (2011) Lactobacillus sp. as probiotics for human health with special emphasis on colorectal cancer. Indian J Sci Tech 4, 1008-14.

12. Furrie E, Macfarlane S, Kennedy A, Cummings JH, Walsh SV, O’Neil DA, Macfarlane GT (2005) Synbiotic therapy (Bifidobacterium longum/Synergy 1) initiates resolution of inflammation in patients with active ulcerative colitis: a randomised controlled pilot trial. Gut 54, 242-9.

13. Amenta M, Cascio MT, Di Fiore P, Venturini I (2006) Diet and chronic constipation. Benefits of oral supplementation with symbiotic zir fos (Bifidobacterium longum W11 + FOS Actilight). Acta Biomed 77, 157-62.

14. Xiao JZ, et al (2006) Effect of probiotic Bifidobacterium longum BBS36 in relieving clinical symptoms and modulating plasma cytokine levels of Japanese cedar pollinosis during the pollen season. A randomized double-blind, placebo-controlled trial. $J$ Investig Allergol Clin Immunol 16, 86-93.

15. Park YH, Kim JG, Shin YW, Kim HS, Kim YJ, Chun 
T, Kim SH, Whang KY (2008) Effects of Lactobacillus acidophilus 43121 and a mixture of Lactobacillus casei and Bifidobacterium longum on the serum cholesterol level and fecal sterol excretion in hypercholesterolemia-induced pigs. Biosci Biotechnol Biochem 72, 595-600.

16. Wildt S, et al (2006) Probiotic treatment of collagenous colitis: A randomized, double-blind, placebocontrolled trial with Lactobacillus acidophilus and Bifidobacterium animalis subsp. lactis. Inflamm Bowel Dis 12, 395-401.

17. Liévin-Le Moal V, Sarrazin-Davila LE, Servin AL (2007) An experimental study and a randomized, double-blind, placebo-controlled clinical trial to evaluate the antisecretory activity of Lactobacillus acidophilus strain LB against nonrotavirus diarrhea. Pediatrics 120, e795-803.

18. Beausoleil M, Fortier N, Guénette S, L'Ecuyer A, Savoie M, Franco M, Lachaîne J, Weiss K (2007) Effect of a fermented milk combining Lactobacillus acidophilus CL1285 and Lactobacillus casei in the prevention of antibiotic-associated diarrhea: A randomized, double-blind, placebo-controlled trial. Can $J$ Gastroenterol 21, 732-6.

19. Kim JY, Choi YO, Ji GE (2008) Effect of oral probiotics (Bifidobacterium lactis AD011 and Lactobacillus acidophilus AD031) administration on ovalbumin-induced food allergy mouse model. J Microbiol Biotechnol 18, 1393-400.

20. Basu S, Paul DK, Ganguly S, Chatterjee M, Chandra PK (2009) Efficacy of high-dose Lactobacillus rhamnosus GG in controlling acute watery diarrhea in Indian children: A randomized controlled trial. J Clin Gastroenterol 43, 208-13.

21. Liu F, Li G, Wen K, Bui T, Cao D, Zhang Y, Yuan L (2010) Porcine small intestinal epithelial cell line (IPEC-J2) of rotavirus infection as a new model for the study of innate immune responses to rotaviruses and probiotics. Viral Immunol 23, 135-49.

22. Maragkoudakis PA, Chingwaru W, Gradisnik L, Tsakalidou E, Cencic A (2010) Lactic acid bacteria efficiently protect human and animal intestinal epithelial and immune cells from enteric virus infection. Int $J$ Food Microbiol 141, S91-7.

23. Ménard S, et al (2005) Bifidobacterium breve and Streptococcus thermophilus secretion products enhance $\mathrm{T}$ Helper 1 immune response and intestinal barrier in mice. Exp Biol Med 230, 749-56.

24. Tooley KL, Howarth GS, Lymn KA, Lawrence A, Butler RN (2006) Oral ingestion of Streptococcus thermophilus diminishes severity of small intestinal mucositis in methotrexate treated rats. Canc Biol Ther 5, 593-600.

25. Rodríguez C, Medici M, Mozzi F, Font de Valdez G (2010) Therapeutic effect of Streptococcus thermophilus CRL 1190-fermented milk on chronic gastritis. World J Gastroenterol 16, 1622-30.
26. Conway PL, Gorbach SL, Goldin BR (2014) Survival of lactic acid bacteria in the human stomach and adhesion to intestinal cells. $J$ Dairy Sci 70, 1-12.

27. Gómez Zavaglia A, Guillermo K, Pérez P, De Antoni $\mathrm{G}$ (1998) Isolation and characterization of Bifidobacterium strains for probiotic formulation. $J$ Food Protect 7, 865-73.

28. Gilliland SE, Walker DK (2014) Factors to consider when selecting a culture of Lactobacillus acidophilus as a dietary adjunct to produce a hypocholesterolemic effect in humans. J Dairy Sci 73, 905-11.

29. Fávaro-Trindade CS, Grosso CRF (2002) Microencapsulation of $L$. acidophilus (La-05) and B. lactis (Bb-12) and evaluation of their survival at the $\mathrm{pH}$ values of the stomach and in bile. $J$ Microencapsul 19, 485-94.

30. Donnet-Hughes A, Rochat F, Serrant P, Aeschlimann JM, Schiffrin EJ (2014) Modulation of nonspecific mechanisms of defense by lactic acid bacteria: effective dose. J Dairy Sci 82, 863-9.

31. Tannock GW, Munro K, Harmsen HJM, Welling GW, Smart J, Gopal PK (2000) Analysis of the fecal microflora of human subjects consuming a probiotic product containing Lactobacillus rhamnosus DR20. Appl Environ Microbiol 66, 2578-88.

32. Yamano $\mathrm{T}$, Iino $\mathrm{H}$, Takada $\mathrm{M}$, Blum $\mathrm{S}$, Rochat $\mathrm{F}$, Fukushima Y (2006) Improvement of the human intestinal flora by ingestion of the probiotic strain Lactobacillus johnsonii La1. Br J Nutr 95, 303-12.

33. Kim S, Suda W, Kim S, Oshima K, Fukuda S, Ohno H, Morita H, Hattori M (2013) Robustness of gut microbiota of healthy adults in response to probiotic intervention revealed by high-throughput pyrosequencing. DNA Res 20, 241-53.

34. Yoon JS, et al (2014) Effect of multispecies probiotics on irritable bowel syndrome: A randomized, doubleblind, placebo-controlled trial. $J$ Gastroenterol Hepatol 29, 52-9.

35. Gayathri A, Gayathri D (2012) Antagonistic properties of Lactobacillus fermentum and L. plantarum with potential intestinal pathogens; purification and characterization of bacteriocin isolated from curd and fecal samples. Adv J Food Sci Tech 4, 265-9.

36. Gayathri D, Rashmi BS (2014) Development of celiac disease; pathogenesis and strategies to control: A molecular approach. $J$ Nutr Food Sci 4, 310.

37. Asha, Gayathri D, Batish V (2012) Molecular characterization and variation of Lactobacillus sp. of remote malnad regions of Karnataka, India. Adv Environ Biol 6, 481-6.

38. Cox AJ, West NP, Horn PL, Lehtinen MJ, Koerbin G, Pyne DB, Lahtinen SJ, Fricker PA, Cripps AW (2014) Effects of probiotic supplementation over 5 months on routine haematology and clinical chemistry measures in healthy active adults. Eur J Clin Nutr 68, 1255-7. 